\title{
AÇÕES E ESTRATÉGIAS DE INCLUSÃO NO PLANO MUNICIPAL DE EDUCAÇÃO DE JATAÍ - GO: FOCO NO TRANSTORNO DO ESPECTRO AUTISTA ${ }^{1}$
}

\author{
LAYS MONEZI MONTEL \\ RITA RODRIGUES DE SOUZA \\ LAÍSSE SILVA LEMOS \\ Instituto Federal de Educação, Ciência e Tecnologia de Goiás (IFG), Jataí, Goiás, Brasil
}

\begin{abstract}
Resumo: O Transtorno do Espectro Autista (TEA) é um dos transtornos do neurodesenvolvimento caracterizado também por comportamentos excessivamente repetitivos, interesses restritos e insistência na mesma coisa, além dos déficits de comunicação e interação social. O presente artigo apresenta uma análise das ações e estratégias propostas para a inclusão de alunos com TEA no ensino básico do município de Jataí-GO. Para isso, identificou-se a meta 04, do Plano Municipal de Educação do município de Jataí-GO, relacionada ao assunto, e selecionou-se somente as estratégias que de algum modo atendem às necessidades do aluno com TEA. Posteriormente, analisou-se também o Relatório de Atividades (biênio 2015-2017) para verificar se essas estratégias já estavam em execução. Após a análise, observou-se que as estratégias abordam de maneira genérica o TEA e as práticas educativas pedagógicas a serem adotadas, sendo mais evidente apenas a criação do Atendimento Educacional Especializado (AEE) em contraturno.
\end{abstract}

Palavras-chave: Transtorno do Espectro Autista. Inclusão Escolar. Práticas Pedagógicas. Plano Municipal de Educação.

\section{INTRODUÇÃO}

O Transtorno do Espectro Autista (TEA) pode ser definido como um distúrbio do neurodesenvolvimento do sujeito presente, em grande maioria dos casos, desde a infância. Caracteriza-se por dificuldades de interação e comunicação que podem ser associadas a alterações sensoriais, comportamentos estereotipados e/ou interesses repetitivos e restritos (AMERICAN PSYCHIATRIC ASSOCIATION - APA, 2014).

\footnotetext{
${ }^{1}$ O presente artigo, inicialmente, foi apresentado como requisito necessário para a Conclusão do Curso de Pós-graduação lato sensu em Docência na Educação Profissional Técnica e Tecnológica Modalidade a Distância, ofertado pelo Instituto Federal de Goiás (IFG) - Campus Jataí-GO em parceria com a Universidade Aberta do Brasil (UAB). Segue, com alterações a partir das contribuições dos pareceristas da Revista Interação, a quem agradecemos.
}

Inter-Ação, Goiânia, v.46, n.1, p. 17-33, jan./mar. 2021. Disponível em: <http://dx.doi.org/10.5216/ia.v45i3.64965>. 
Com base nas características supracitadas, é importante que o poder público, seja municipal, estadual ou federal, promova condições básicas para que as instituições públicas de ensino possam oferecer recursos específicos para atender a demanda de alunos com TEA. Para que a relação ensino-aprendizagem desses alunos seja tão eficaz quanto a relação dos alunos que não apresentam o transtorno.

Os desafios em sala de aula aumentam a cada ano, principalmente porque são cada vez mais frequentes nas escolas, crianças e adolescentes que necessitam de um maior cuidado no que diz respeito ao seu processo de escolarização. São alunos com diferentes necessidades, sejam elas físicas, visuais, intelectuais, altas habilidades/superdotação e, mais recentemente, aqueles com TEA. De acordo com Tokarnia (2019), no período de 2014 a 2018, observou-se um aumento de 33,2\% no número de matrículas de estudantes com necessidades especiais nas escolas brasileiras, representando um indício de inclusão escolar desse público.

Para a consolidação do processo de inclusão nas escolas, é necessário, no entanto, o aprimoramento das metodologias educativas e pedagógicas, bem como o uso de diferentes recursos pedagógicos e, principalmente, do preparo das escolas e dos educadores para que possam bem atender e amparar os alunos com suas diferentes especificidades (BRASIL, 2014a; ROSA; MONTEIRO; MANZINI, 2008 apud CABRAL; MARIN, 2017).

Com base na necessidade de analisar como escolas e docentes estão se preparando para esse processo, o presente artigo apresenta uma pesquisa que objetivou, principalmente, elucidar, por meio da análise documental do Plano Municipal de Ensino (PME) de Jataí-GO, em vigência (Lei n 3.708 de 26 de junho de 2015), quais são as estratégias propostas para a inclusão de alunos com TEA do ensino básico em Jataí-GO. Como objetivos específicos, buscou-se: analisar o PME e o Relatório de Avaliação do PME referente ao biênio 2015-2017; identificar as metas que se referem à inclusão; e verificar as estratégias descritas que visam à melhoria da educação municipal em relação à inclusão.

Para a apresentação do desenvolvimento e resultados da pesquisa, este artigo traz, primeiramente, um referencial teórico abordando em relevo o tema TEA e a inclusão desses alunos no Brasil. Na sequência, a metodologia, que apresenta como este estudo foi delineado e o modo de obtenção dos dados por meio da pesquisa exploratória documental. Depois, elenca e discute as estratégias relacionadas ao TEA, assim como apresenta uma análise do Relatório de Atividades (2017) de execução das metas propostas no PME, atinentes à inclusão.

\section{REFERENCIAL TEÓRICO}

\section{TRANSTORNO DO ESPECTRO AUTISTA (TEA)}

A Classificação Internacional de Doenças - (DSM-5, 2014), oficialmente adotada pela legislação brasileira, padronizada pela Organização Mundial da Saúde (OMS), classifica o autismo, o transtorno desintegrativo da infância e a síndrome de Asperger com um único diagnóstico, chamado de Transtorno do Espectro Autista - TEA. Conforme 
MONTEL. L. M.; SOUZA, R. R. DE, LEMOS, L. S

esse documento, os TEA foram incluídos como parte de um grupo denominado Transtornos do Neurodesenvolvimento que podem se manifestar muito cedo, antes mesmo do ingresso das crianças na escola.

De acordo com o Manual Diagnóstico e Estatístico de Transtornos Mentais (DSM-5, 2014), o portador de TEA tem como características: déficits persistentes na comunicação e na interação social, assim como, padrões restritos de atividades, interesses e comportamento. As manifestações do transtorno são variáveis, a depender do nível de desenvolvimento e da idade cronológica. O TEA se caracteriza

\begin{abstract}
por déficits persistentes na comunicação social e na interação social em múltiplos contextos, incluindo déficits na reciprocidade social, em comportamentos não verbais de comunicação usados para interação social e em habilidades para desenvolver, manter e compreender relacionamentos. Além dos déficits na comunicação social, o diagnóstico do transtorno do espectro autista requer a presença de padrões restritos e repetitivos de comportamento, interesses ou atividades (DSM, 2014, p. 31).
\end{abstract}

O diagnóstico de TEA é basicamente clínico, partindo de observações da criança, de entrevistas realizadas com os pais e de aplicação de instrumentos específicos. Os critérios para o diagnóstico de TEA são descritos no Manual Estatístico e Diagnóstico DSM-5, elaborado pela Associação Americana de Psiquiatria (GOMES et al., 2015).

O Manual de Orientação do Departamento Científico de Pediatria do Desenvolvimento e Comportamento (2019, p. 16) alerta que "o tratamento considerado padrão-ouro para o TEA é a intervenção precoce, a ser realizado logo que se tenha a suspeita ou imediatamente após o diagnóstico por uma equipe interdisciplinar". As intervenções psicossociais baseadas em evidências, como o tratamento comportamental e os programas de treinamento de habilidades para os pais, visam aumentar o potencial da comunicação e desenvolvimento social, com o intuito de melhorar a qualidade de vida das pessoas com TEA e dos cuidadores (OPAS, 2017).

\title{
A INCLUSÃO DE ALUNOS COM TEA NO BRASIL
}

Na última década, houve um crescimento considerável de crianças e jovens com TEA frequentando escolas de ensino regular. Esse aumento se deve à incansável luta de pais e familiares pelos direitos da pessoa com deficiência e pela sua plena inclusão na sociedade. Em 27 de dezembro de 2012, foi instituída a Lei n 12.764/2012 Lei Berenice Piana, que estabeleceu a Política Nacional de Proteção dos Direitos da Pessoa com TEA, prevendo o acesso a um sistema educacional inclusivo em todos os níveis de ensino e atendimento por profissionais capacitados a desenvolver atividades com vistas à inclusão (BENINI; CASTANHO, 2016). Segundo o dicionário Aurélio online, a palavra "inclusão" apresenta várias acepções, uma delas significa "introdução de algo em; ação de acrescentar, de adicionar algo no interior de; inserção" (DIClO, s/p), e, mais precisamente na educação, significa "integração absoluta de pessoas que possuem necessidades especiais ou específicas numa sociedade: políticas de inclusão" (DICIO, $\mathrm{s} / \mathrm{p}$ ). Isto é, a política educacional inclusiva consiste em inserir indivíduos com 
necessidades especiais em turmas regulares, fazendo-os participar de todos os tipos de atividades, sejam elas educacionais, comunitárias, esportivas ou sociais.

Em 08 de janeiro de 2020 foi sancionada a Lei 13.997/2020, denominada "Lei Romeo Mion", que altera a Lei no 12.764, de 27 de dezembro de 2012 (Lei Berenice Piana), e a Lei no 9.265, de 12 de fevereiro de 1996 (Lei da gratuidade dos atos da cidadania), para instituir a Carteira de Identificação da Pessoa com Transtorno do Espectro Autista (Ciptea), e dá outras providências (BRASIL, 2020). Com isso, já é possível observar que a inserção do TEA nas políticas públicas no Brasil vem ocorrendo gradualmente.

Estima-se que, em todo o mundo, o transtorno do espectro autista afete uma em cada 160 crianças. Porém, devido à variação entre os estudos, essa estimativa representa apenas um valor médio (OPAS, 2017). Os dados epidemiológicos também mostram que essa síndrome acomete mais o sexo masculino (GOMES et al., 2015) numa proporção de 4:1 ou 5:1, no entanto, quando as meninas são afetadas, o transtorno tende a ser mais severo (KLIM, 2006).

Sobre a prevalência de TEA no Brasil, não existem números oficiais. Apenas um estudo piloto publicado no ano de 2011, com uma população de 20 mil pessoas, no interior de São Paulo que resultou em 1 autista para cada 367 crianças (RIBEIRO et al., 2011, PAIVA $J R$, 2019). De acordo com estimativas globais da Organização da Nações Unidas (ONU), aproximadamente $1 \%$ da população é autista. Conforme projeção do Instituto Brasileiro de Geografia e Estatística (IBGE), a população brasileira tinha ultrapassado 208 milhões de habitantes em 2018. Desta forma, com base nessas projeções, seriam aproximadamente 2 milhões de pessoas com autismo no Brasil (PAIVA JR, 2019). Segue infográfico, Figura 1, com informações sobre o TEA:

Figura 1:TEA

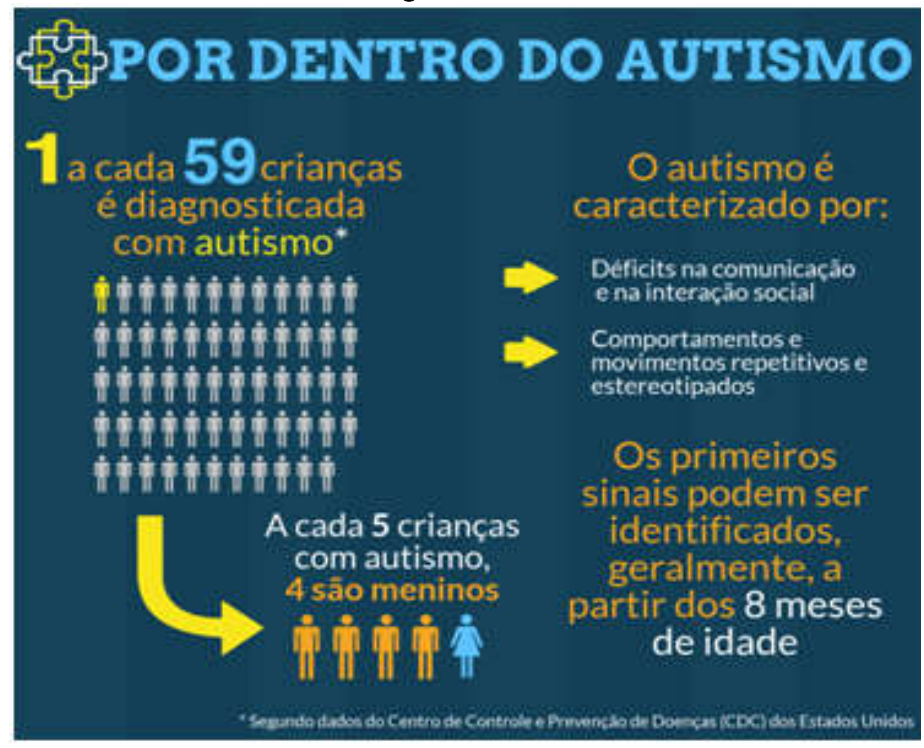

Inter-Ação, Goiânia, v.46, n.1, p. 17-33, jan./mar. 2021. Disponível em: <http://dx.doi.org/10.5216/ia.v45i3.64965>. 
MONTEL. L. M.; SOUZA, R. R. DE, LEMOS, L. S

Fonte: Tavares e Stachewski (2017)

No entanto, em julho de 2019, entrou em vigor a Lei $n^{\circ} 13.861$ que altera a Lei no 7.853, de 24 de outubro de 1989, para incluir as especificidades inerentes ao TEA nos censos demográficos (BRASIL, 2019). Com isso, brevemente, teremos dados mais consistentes em relação ao número de autistas no Brasil.

Em relação ao número de crianças com necessidades especiais matriculadas nas escolas, de 2014 a 2018 esse número subiu 33,2\% em todo Brasil, de acordo com dados do Instituto Nacional de Estudos e Pesquisas Educacionais Anísio Teixeira (Inep). Os dados mostram que, no ano de 2014, foram matriculados no Brasil, 886.815 alunos com deficiência, altas habilidades e transtornos globais do desenvolvimento, e esse número aumenta a cada ano. Sendo que no ano de 2018, esses números chegaram a 1,2 milhão de matriculados. Somente entre os anos de 2017 e 2018, o aumento foi de aproximadamente 10,8\% nas matrículas (TOKARNIA, 2019).

A escola torna-se então um recurso fundamental para enriquecer as experiências sociais das crianças com TEA, oferecendo a elas oportunidade de interagirem com outras crianças. Contribui assim para o desenvolvimento de novas aprendizagens e comportamentos (NUNES; AZEVEDO; SCHIMIDT, 2013).

Vejamos a Figura 2, ela mostra também informações sobre a prevalência do TEA:

Figura 2: Prevalência TEA

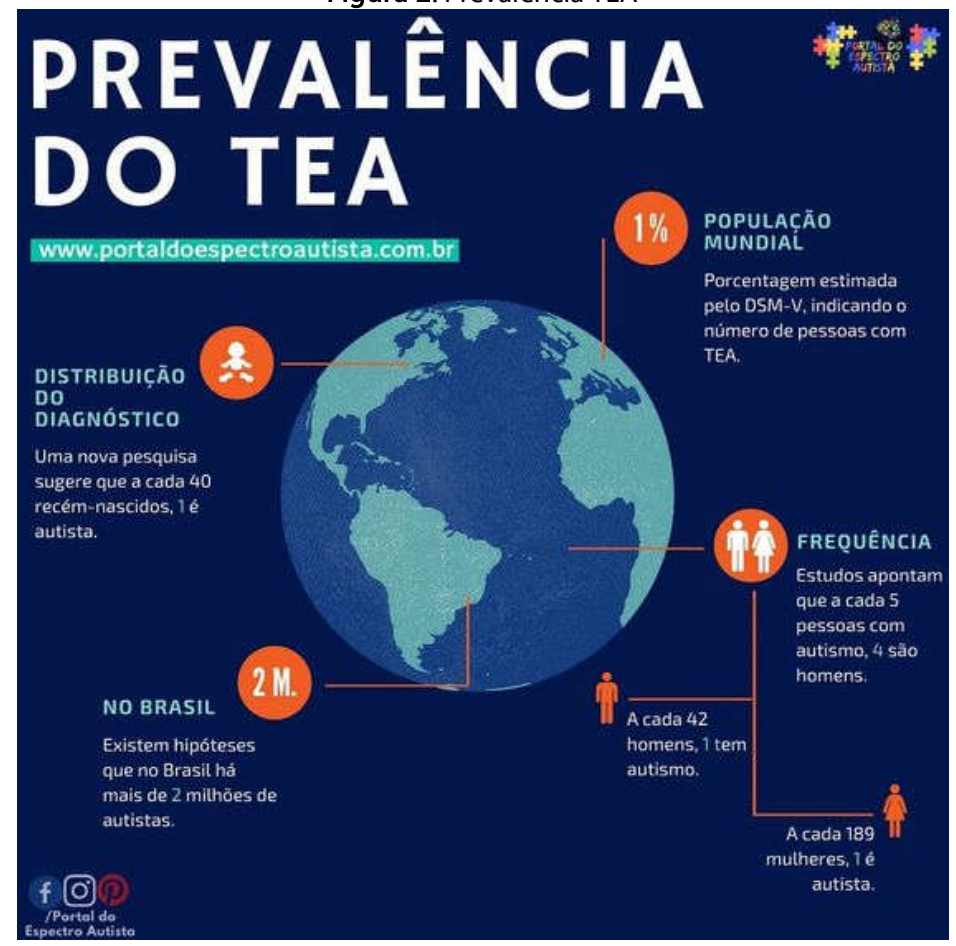

Fonte: Portal do Espectro Autista (2020). 
O Conselho Nacional de Educação (CNE) publicou uma resolução em 2009 (CNE/CEB) que institui as Diretrizes Operacionais para o Atendimento Educacional Especializado (AEE) na Educação Básica. Em seguida, no ano de 2010, houve uma ratificação desta resolução que preconiza que os sistemas de ensino devem matricular os estudantes com deficiência, transtornos globais do desenvolvimento e altas habilidades/superdotação nas escolas do ensino regular e no $A E E$, de forma complementar ou suplementar à escolarização (BRASIL, 2014a).

O AEE tem como função identificar, elaborar e organizar recursos pedagógicos e de acessibilidade que eliminem as barreiras para a plena participação dos alunos nas escolas públicas e privadas, considerando suas necessidades específicas. As atividades ofertadas nas salas do AEE devem se distinguir daquelas realizadas em sala de aula regular, de forma a complementar e/ou suplementar ao processo de aprendizagem dos alunos, mas não substituindo a escolarização ofertada pelas redes municipal, estadual e federal. Vale ressaltar que no decorrer do processo de escolarização esse atendimento deve estar relacionado à proposta pedagógica de ensino prevista nos documentos oficiais (BRASIL, 2014a).

Dentre as atividades de $\mathrm{AEE}$, são disponibilizados programas de enriquecimento curricular, o ensino de linguagens e códigos específicos de comunicação e sinalização, e tecnologia assistiva. O ensino é acompanhado com ferramentas que possibilitem monitoramento e avaliação da oferta realizada nas escolas da rede pública e nos centros de atendimento educacional especializados públicos ou conveniados (BRASIL, 2014a).

As ferramentas são interpretadas como um conjunto de ações que envolve o Projeto Político Pedagógico da escola. Elas devem contemplar o entendimento de acesso, permanência e êxito dos alunos com necessidade especiais. Gestor, grupo de docentes e comunidade local ficam responsáveis pela implementação de práticas e instalação de salas de $\mathrm{AEE}$, mapeamento de matrícula, especificando a necessidade especial de cada educando, e o Governo dá o suporte material, financeiro e logístico, tais como:

\footnotetext{
- Atualização: novos itens às salas já implantadas, com matrícula de alunos público-alvo da educação especial;

- Conversão: itens da sala Tipo II às salas de Tipo I implantadas, com matrícula de aluno(s) cego(s) em classe comum²;

- Apoio complementar: Programa Escola Acessível e do Programa de Formação Continuada de Professores na Educação Especial;

- Visita Técnica: verificação do funcionamento e dos itens da sala, realizada por técnico do MEC/SEESP;
}

\footnotetext{
2 "O Programa de Implantação de Salas de Recursos Multifuncionais disponibiliza equipamentos, mobiliários, materiais didáticos e pedagógicos para a organização das salas e a oferta do atendimento educacional especializado - AEE" (BRASIL, 2010, p. 11). O Manual de Orientação: Programa de Implantação de Sala de Recursos Multifuncionais traz as especificações das salas Tipo I e Tipo II.
}

Inter-Ação, Goiânia, v.46, n.1, p. 17-33, jan./mar. 2021. Disponível em: <http://dx.doi.org/10.5216/ia.v45i3.64965>. 
MONTEL. L. M.; SOUZA, R. R. DE, LEMOS, L. S

- Informativos: encaminhamento da Revista Inclusão e outras publicações pedagógicas do MEC/SEESP. (MEC 2010, p. 16)

Aportada nas deliberações da Conferência Nacional de Educação - CONAE/ 2010, a Lei no 13.005/2014, que instituiu o Plano Nacional de Educação - PNE, no inciso III, parágrafo $1^{\circ}$, do artigo $8^{\circ}$, determina que os Estados, o Distrito Federal e os Municípios garantam o atendimento das necessidades específicas na educação especial, assegurando o sistema educacional inclusivo em todos os níveis, etapas e modalidades (BRASIL, 2014a). Para que os direitos do cidadão sejam garantidos e para que o país tenha educação de qualidade e para todos, é essencial que o PNE e os planos de educação do estado e do município atuem em conjunto de modo coerente, integrado e articulado (BRASIL, 2014b).

Diante desse contexto e dos dados apresentados acima, percebeu-se a necessidade de se realizar um estudo analisando o Plano Municipal de Ensino (PME) do município de Jataí-GO, a fim de elucidar quais são as estratégias voltadas para as crianças com TEA do referido município. Em especial, os educandos com TEA estão amparados por um conjunto de leis, decretos, normas da educação inclusiva, porém necessitam que esse aparato legal impacte nas práticas pedagógicas escolares para que tenham uma educação de qualidade.

A generalização que engloba de forma conjunta os alunos com necessidades especiais, sob a tutela do slogan: "educação inclusiva", possibilitou o ingresso - matrícula - do alunado na rede regular, mas não logrou por sua permanência e sucesso no processo de ensino e aprendizagem. Esses alunos têm direito a um espaço ímpar, pois, no caso, alunos com TEA demandam atendimento dinâmico, adequações no currículo para atender as suas necessidades, formação de professores, adequação dos espaços físicos da escola e material didático que precisa ser, de forma contínua, reinventado a cada novo aluno.

\section{MetOdOLOGIA}

Para a obtenção das respostas ao problema em questão, anteriormente apresentado, realizou-se a pesquisa exploratória documental. Segundo Gil (2002), a pesquisa exploratória visa possibilitar a familiarização com o problema, a fim de torná-lo mais explícito ou a constituir hipóteses. Para Marques (2014), a pesquisa é considerada exploratória quando se aproxima do tema pela primeira vez, com o objetivo de se chegar ao problema específico e estabelecer hipóteses, com vistas a estudos posteriores. Umas das técnicas utilizadas para o desenvolvimento deste tipo de pesquisa é a análise documental.

Na pesquisa documental, a coleta dos dados primários se dá mediante análises de documentos de forma geral (MARQUES, 2014). As fontes podem ser diversificadas e dispersas. Neste tipo de pesquisa, há os documentos que ainda não receberam tratamento analítico de órgãos públicos e instituições privadas (por exemplo, associações científicas, igrejas, sindicatos). Envolvem também aqueles documentos que de alguma forma já foram analisados, tais como: relatório de pesquisa, relatório de empresas, tabelas estatísticas (GIL, 2002). 
Os objetos de estudo desta pesquisa são: o Plano Municipal de Ensino - PME do município de Jataí-GO, aprovado pela câmara municipal de Jataí por meio da Lei $\mathrm{n}^{\circ}$ 3.708 de 26 de junho de 2015, com vigência de dez anos a contar da data da sua publicação, e do Relatório de Avaliação do PME referente ao biênio 2015-2017, único publicado até a data de realização deste trabalho. Ambos os documentos estão disponíveis para consulta no site da Prefeitura Municipal de Jataí, no link. https://www.jatai.go.gov.br/secretaria-de-educacao/plano-municipal-de-educacao/.

O PME é composto por 20 (vinte) metas a serem cumpridas no período de vigência de 2015 a 2025. Para cada meta, são descritas diversas estratégias a serem implementadas para garantir seu cumprimento. Foi selecionada para este estudo, somente a meta que retrata a educação especial e inclusiva, como também as estratégias correspondentes, a fim de identificar quais são as ações descritas e as estratégias propostas para efetivar a inclusão de alunos com TEA no ensino básico no município de Jataí-GO. Em seguida, selecionou-se somente as estratégias que, de alguma forma, atendem as necessidades do aluno com TEA. Seja no que tange à estrutura escolar, à capacitação dos professores para atender os alunos com TEA, AEE e parceria com equipe multiprofissional.

Posteriormente, analisou-se também o Relatório de Avaliação do PME (biênio 2015-2017), disponibilizado pelo portal da Prefeitura de Jataí. Esse documento tem como finalidade acompanhar e monitorar a execução das estratégias descritas no PME, bem como, a partir delas verificar a evolução do cumprimento da meta estabelecida. $O$ Relatório de Avaliação é apresentado por uma comissão de monitoramento e avaliação, formada por representantes de instituições de educação do município.

\section{APRESENTAÇÃO E ANÁLISE DOS DADOS}

Após leitura do PME, do município de Jataí-GO, foi possível identificar dentre as 20 metas, a meta 04 e suas respectivas estratégias como correspondentes à educação especial e inclusiva, que segue transcrita no Quadro 1:

Quadro 1: Meta 4

META 04: Universalizar, para a população de 4 (quatro) a 17 (dezessete) anos com deficiência, transtornos globais do desenvolvimento e altas habilidades ou superdotação, o acesso à educação básica e ao atendimento educacional especializado, preferencialmente na rede regular de ensino, com a garantia de sistema educacional inclusivo, de salas de recursos multifuncionais, classes, escolas ou serviços especializados, públicos ou conveniados.

Fonte: PME - Jataí-GO (2015)

Com uma redação simples, a meta 4 apresenta como finalidade difundir o acesso à educação básica e ao AEE para crianças e adolescentes na rede regular de ensino, garantindo a educação inclusiva. Como já mencionado anteriormente, e cabe aqui ressaltar, o AEE tem o objetivo de elaborar e organizar recursos pedagógicos e de acessibilidade que possibilitem envolver mais o aluno nas escolas regulares e facilitar seu aprendizado, considerando suas necessidades especiais (BRASIL, 2014a). 
MONTEL. L. M.; SOUZA, R. R. DE, LEMOS, L. S

A meta 4 é composta por 16 estratégias. Dessas, destacam-se em itálico, no Quadro 2, as estratégias $2,4,5,7,8,11,12$ e 15 , que estão direta ou indiretamente relacionadas ao TEA:

\section{Quadro 2: Estratégias da meta 4}

1. Adaptar edifícios escolares para o atendimento a alunos com necessidades especiais, garantindo a acessibilidade e mobilidade adequada.

2. Implementar, em cinco (5) anos a partir da vigência deste plano, política de padrões mínimos de infraestrutura física da rede, com prédios, número adequado de salas de aula, auditórios, dependências administrativas, quadras de esporte, bibliotecas, laboratórios, equipamentos de multimídia, telefones, reprodutores de textos.

3. Em parceria entre Secretaria Municipal de Educação e Instituições de Ensino Superior pública, a partir de 2016, oferecer cursos de formação inicial e continuada para professores na Língua Brasileira de Sinais e no Sistema Braille, e metodologias específicas para educandos surdos, cegos, e demais necessidades especiais em todas as etapas da educação.

4. Garantir a partir de agosto de 2015, a continuidade das Salas de Atendimento de Ensino Especializado, em horário integral, a ser oferecido em turno contrário ao de estudo do aluno, com material pedagógico adaptado, nas escolas da rede regular nas escolas urbanas.

5. Garantir o acesso à matrícula e à flexibilização curricular de estudantes com deficiência visual, auditiva, física, intelectual, transtornos globais do desenvolvimento e altas habilidades ou superdotação na rede regular de ensino.

6. Garantir transporte adaptado casa/escola/casa e casa/centro de atendimento/casa aos alunos portadores de necessidades especiais consideráveis, para escolas urbanas.

7. Promover, em parceria com diferentes instituições, cursos de capacitação em áreas de demanda relacionadas à educação especial, voltados à comunidade escolar.

8. Firmar convênios e parcerias com instituições e ONGs promovendo a ampliação do atendimento às pessoas com deficiência.(sic)

9. Viabilizar a partir do ano de 2018 o atendimento especializado independente da idade.

10. Buscar mecanismos para localizar até o final de 2017, alunos portadores de necessidades especiais consideráveis e estabelecer estratégias de atendimento.

11. Adquirir e disponibilizar materiais didáticos e pedagógicos, recursos de tecnologia assistiva, equipamentos e mobiliário adaptados para alunos com necessidades especiais.

12. Fazer gestões junto à Secretaria de Saúde e sugerir a criação de centros multidisciplinares de apoio, pesquisa e assessoria articulados com instituiçóes acadêmicas e integrados por profissionais das áreas de saúde, educação e promoção social (Neurologistas, Psiquiatras, Psicólogos e Fonoaudiólogos, Assistente Social e Pedagogos, dentre outros) para acompanhar famílias e alunos com transtornos físico, mental e psicológico e família.

13. Criar até 2017, salas em conformidade com a demanda, em escolas de tempo integral, bilíngue para surdos, que contemple a aquisição da Língua Brasileira de Sinais como primeira língua (L1), e a aquisição da Língua Portuguesa como segunda língua (L2), na modalidade escrita. A referida sala contemplará a oferta de educação infantil e/ou ensino fundamental, com quadro docente habilitado em proficiência em Libras e apoio de equipe multiprofissional.

14.Desenvolver ações individualizadas, no contraturno, em salas de atendimento educacional especializado, para alfabetizar crianças e adultos cegos, na educação infantil e no ensino fundamental. 15. Garantir a presença de um professor de apoio para atendimento por sala, para um grupo de até (seis) 6 alunos.

16. Buscar em parceria com a Secretaria Municipal de Saúde atendimento médico (neurologista, psiquiatra, oftalmologista, otorrinolaringologista, ortopedista, dentre outras) para diagnosticar deficiência e formalizar laudo médico.

Fonte: Adaptado durante a pesquisa de PME (2015). 
O Quadro 2 reforça questões já levantadas: um arcabouço de leis que positivam a educação inclusiva, com tratamento pormenorizado para surdos e cegos, e colocando o TEA como: demais necessidades especiais. Isso dificulta uma real formação docente, já que as diversas necessidades especiais agrupam linha de estudo, cuidado e gestão de aula ímpares.

Ao analisar as 16 estratégias descritas no PME, foi possível identificar e distinguir aquelas que podem atender as necessidades dos alunos com TEA, direta ou indiretamente. Enquadram-se na proposta deste estudo metade das estratégias da meta 4. Elas foram destacadas no Quadro 2, a saber: 2, 4, 5, 7, 8, 11, 12 e 15.

Sendo que as estratégias 4, 5, 8, 12 e 15 envolvem diretamente o aluno com TEA, pois buscam garantir o acesso desse aluno à sala de aula, reforçar seu aprendizado por meio das salas de $A E E$, disponibilizar professores de apoio, além de firmar parcerias com ONG e equipes multiprofissionais que visam ampliar o atendimento às pessoas com deficiências e seus familiares. Seguem transcritas essas estratégias e negritadas as palavras e expressões que remetem à inclusão e ao TEA:

4. Garantir a partir de agosto de 2015, a continuidade das Salas de Atendimento de Ensino Especializado, em horário integral, a ser oferecido em turno contrário ao de estudo do aluno, com material pedagógico adaptado, nas escolas da rede regular nas escolas urbanas.

5. Garantir o acesso à matrícula e à flexibilização curricular de estudantes com deficiência visual, auditiva, física, intelectual, transtornos globais do desenvolvimento e altas habilidades ou superdotação na rede regular de ensino. 8. Firmar convênios e parcerias com instituições e ONGs promovendo a ampliação do atendimento às pessoas com deficiência. (sic)

12. Fazer gestões junto à Secretaria de Saúde e sugerir a criação de centros multidisciplinares de apoio, pesquisa e assessoria articulados com instituições acadêmicas e integrados por profissionais das áreas de saúde, educação e promoção social (Neurologistas, Psiquiatras, Psicólogos e Fonoaudiólogos, Assistente Social e Pedagogos, dentre outros) para acompanhar familias e alunos com transtornos físico, mental e psicológico e família.

15. Garantir a presença de um professor de apoio para atendimento por sala, para um grupo de até (seis) 6 alunos.

Já as estratégias 2 e 11 visam melhorar a infraestrutura das escolas, aquisição de materiais didáticos e pedagógicos, que de forma indireta despertam o interesse do aluno em aprender. Assim, como a estratégia 7, que tem como objetivo promover, em parcerias com diferentes instituições, cursos de capacitação em áreas de demanda relacionadas à educação especial. Deste modo, os educadores estarão mais preparados para atender o aluno com TEA. Seguem transcritas essas estratégias e negritadas as palavras e expressões que remetem à inclusão e ao TEA:

2. Implementar, em cinco (5) anos a partir da vigência deste plano, política de padrões mínimos de infraestrutura física da rede, com prédios, número adequado de salas de aula, auditórios, dependências administrativas, quadras de esporte, bibliotecas, laboratórios, equipamentos de multimídia, telefones, reprodutores de textos. 
MONTEL. L. M.; SOUZA, R. R. DE, LEMOS, L. S

\section{Promover, em parceria com diferentes instituições, cursos de capacitação em áreas de demanda relacionadas à educação especial, voltados à comunidade escolar. 11. Adquirir e disponibilizar materiais didáticos e pedagógicos, recursos de tecnologia assistiva, equipamentos e mobiliário adaptados para alunos com necessidades especiais.}

Por fim, por meio do Relatório de Avaliação (2005-2017), analisou-se todas as informações referentes às estratégias selecionadas para verificar o andamento e o cumprimento de cada uma delas nas instituições de ensino básico do município. Ressalta-se que, no Relatório de Avaliação, há o registro de que os avaliadores não obtiveram dados de escolas particulares: "O grupo não obteve respostas referentes aos dados das instituições privadas" (RELATÓRIO, 2017, p. 18)

Em relação à estratégia 2, considerou-se que ela já está em andamento. $\mathrm{A}$ Secretaria Municipal de Educação (SME) informou que foi realizado, pelo Núcleo de Acessibilidade e Inclusão (NAI), o levantamento das demandas da acessibilidade e estrutura nas 42 instituições de ensino da rede a fim de mapear as adaptações necessárias em cada uma, assim como planejar para os próximos anos as modificações que ainda necessitam. Ainda segundo a SME, das 13 escolas estaduais, $90 \%$ apresentam estrutura física dentro dos padrões mínimos de acessibilidade exigidos.

No que diz respeito a implantação de salas de $\mathrm{AEE}$ em tempo integral, referente à estratégia 4, a SME informou que possui AEE em funcionamento em todas as escolas da zona urbana. Apenas três delas atendem em meio período, devido à baixa demanda de alunos que necessitam da AEE. Foi informado ainda que projetaram para o ano de 2018 o atendimento em tempo integral, visando acatar plenamente a normativa que rege o AEE. Essas informações indicam que, estão caminhando para o cumprimento desta estratégia, porém, sugere-se que as salas de AEE se estendam também às escolas da zona rural.

Em relação à estratégia 5, sobre o acesso à matrícula e a flexibilização curricular de estudantes com deficiência visual, auditiva, física, intelectual, transtornos globais do desenvolvimento e altas habilidades ou superdotação na rede regular de ensino, a SME informou que $100 \%$ da demanda está sendo atendida. Frente a essa informação, observa-se uma segurança quanto aos pedidos de matrículas serem ativamente efetivados, e como a análise da pesquisa é documental, abre-se a vertente para alguns questionamentos: se esses alunos permanecem(ram) durante todo o ano letivo, se foram para as séries seguintes, como se deu seu aprendizado e se foi adequado, se supriu suas necessidades e sua ambientação na escola? No Relatório (2017) não constam informações que possam responder a esses questionamentos.

A flexibilização é garantida a todos os alunos com todas as deficiências por meio de planejamento quinzenal e das formações periódicas oferecidas pelo departamento de ensino especial da Coordenação Regional de Educação Cultura e Esporte (CRECE). A SME adotou o Plano de Desenvolvimento Individualizado e o Plano de Atendimento Especializado que devem ser preenchidos em todas as instituições que possuem alunos com deficiência. Utiliza também o Princípio do Desenho Universal para a elaboração das aulas, que vem sendo trabalhado nos cursos de formações e orientações pedagógicas. O termo Desenho Universal de Aprendizagem consiste em um conjunto de princípios e estratégias que se relacionam ao desenvolvimento curricular, 
visando eliminar as barreiras ao ensino e à aprendizagem (NUNES; MADUREIRA, 2015). Portanto, considerou-se satisfatório para o cumprimento da estratégia proposta.

De acordo com a avaliação, a estratégia 7 se encontra em andamento, tendo já atendido um índice de $55 \%$ conforme a disponibilidade das universidades do município e do Núcleo de Ensino Especial da SEDUCE-Goiânia. A SME mencionou que a capacitação e formação profissional é uma política da SME e na área de inclusão é pensada pelo NAI, que tem uma proposta de trabalho para o período de 2017 a 2020. Sendo que no ano de 2017 foram ofertados cursos em diferentes áreas: Autismo, Legislação Inclusiva, Libras, Plano de Desenvolvimento Individual e Plano de Ensino Especializado e Primeiros Socorros. Deste modo, foi possível observar que essa proposta já se encontra bem encaminhada.

Sobre a parceria com instituições e ONG, proposta pela estratégia 8, o Relatório (2017) de atividades mostra que, segundo a CRECE, já existiam até o momento parcerias entre o CAEE Érica de Melo Barbosa, Casa Amor e Arte, Pestalozzi e entidades de Ensino Superior de Jataí. Porém, não havia ainda nenhum convênio com entidades da saúde pública para atender os alunos que necessitam de atendimento multiprofissional. Conforme afirmado pela SME, possuem parceria com o MAC, Museu Histórico, APAE, PESTALOZZI, CAEE Érica de Melo Barboza, Casa da Criança Amor \& Arte, CEBRAV Goiânia e CEMOL, visando ampliar as possibilidades educativas, sociais e de reabilitação dos alunos com deficiência da rede pública.

Com base na estratégia 11, algumas escolas estaduais possuem recursos pedagógicos para atender às necessidades especiais dos alunos, porém, existem em todas uma ausência significativa de recursos tecnológicos adaptados. Já nas instituições municipais, segundo a SME, todas se encontram bem servidas. Ao analisar esta avaliação, considerou-se que, para o total cumprimento dessa estratégia, mais recursos precisam ser disponibilizados às escolas estaduais do município.

Já para a estratégia 12, observou-se que essa proposta ainda não está sendo aplicada, pois, segundo a CRECE, estava em planejamento. De acordo com a SME, uma reunião com a Secretária Municipal de Educação e o Secretário Municipal de Saúde, juntamente ao NAl, havia acontecido para discutirem o assunto da formação de uma equipe multidisciplinar de apoio, porém, não ficou claro se isso foi concretizado e/ou se já se encontra em andamento.

Sobre garantir a presença de um professor de apoio para atendimento por sala, avaliação foi positiva, pois, de acordo com a CRECE, cerca de $99 \%$ da demanda possui atendimento individualizado nas deficiências mais severas. A SME afirmou que está atendendo toda a demanda. Salientamos que somente a presença de um professor de apoio não condiciona um atendimento adequado para alunos com TEA, seria necessário avaliar o currículo do profissional e alinhar a formação dele com a necessidade de cada aluno. Além disso, seria mais eficiente a presença de uma equipe multidisciplinar para melhor atender esses alunos.

\section{CONCLUSÕES}


MONTEL. L. M.; SOUZA, R. R. DE, LEMOS, L. S

A pesquisa exploratória documental (GIL, 2002) foi realizada para buscar quais são as estratégias utilizadas para a inclusão e o aprendizado de alunos com TEA do ensino básico no município de Jataí-GO. Deste modo, após analisar a meta 04 e suas estratégias descritas no PME, assim como, as informações extraídas do Relatório de Atividades, observou-se que as estratégias abordam de forma genérica o TEA e as práticas educativas pedagógicas adotadas, sendo mais evidente apenas a criação do AEE em contraturno, conforme instituído pela Política Nacional de Educação Especial na Perspectiva da Educação Inclusiva (BRASIL, 2014a). Essas práticas educativas pedagógicas podem ser materiais e jogos lúdicos que possam despertar o interesse do aluno, por exemplo.

Sugere-se que ao elaborar o PME, as estratégias sejam criadas junto a uma comissão de acessibilidade e inclusão. E que essas sejam apresentadas de formas mais específicas e aprofundadas para facilitar o desenvolvimento e o monitoramento das mesmas. Vale ressaltar que, em relação à estrutura, as instituições públicas de ensino conseguem atender a demanda de alunos com TEA, conforme a avaliação descrita no relatório de atividades. Porém, é importante citar a necessidade de um maior amparo técnico-pedagógico aos educadores e também consolidar a relação entre a família do aluno com TEA e a escola.

Como até o momento da realização deste trabalho, a SME havia publicado apenas o primeiro relatório de atividades referente aos primeiros dois anos da publicação do PME, por isso, muitas estratégias se mostraram no início de sua execução. Sugere-se a realização de um estudo mais aprofundado no que tange a esse assunto, ao final do período de vigência desse PME, para que seja possível obter dados mais sólidos. Como o PME é um documento comum a todos os municípios, é possível que a metodologia utilizada nesta pesquisa também possa se estender a outros municípios, uma vez que se trata de documento público e acessível. Posteriormente, os resultados obtidos poderiam ser comparados entre os municípios e, assim, obter um retrato da inclusão no estado de Goiás.

Artigo recebido em: $17 / 08 / 2020$

Aprovado para publicação em: 03/11/2020

ACTIONS AND INCLUSION STRATEGIES IN THE MUNICIPAL EDUCATION PLAN OF JATAÍ - GO: FOCUS ON THE DISORDER OF THE AUTISTIC SPECTRUM

ABSTRACT: Autistic Spectrum Disorder (ASD) is one of the neurodevelopmental disorders also characterized by excessively repetitive behaviors, restricted interests and insistence on the same thing, in addition to deficits in communication and social interaction. This article presents an analysis of the actions and strategies proposed for the inclusion of students with ASD in basic education in the municipality of Jataí-GO. For this, goal 04, of the Municipal Education Plan of the municipality of Jataí-GO, was identified, related to the subject and only selected strategies that, in some way, meet the needs of the student with ASD. Subsequently, the Activity Report (2015-2017 biennium) was also analyzed to verify whether these strategies were already being implemented. 
After the analysis, it was observed that the strategies approach, in a generic way, the TEA and the pedagogical educational practices to be adopted, being more evident only the creation of the Specialized Educational Service (AEE) in the evening.

KEYWORDS: Autistic Spectrum Disorder. School Inclusion. Pedagogical Practices. Municipal Education Plan.

ACCIONES Y ESTRATEGIAS DE INCLUSIÓN EN EL PLAN DE EDUCACIÓN MUNICIPAL DE JATAÍ - GO: ENFOQUE EN EL TRASTORNO DEL ESPECTRO AUTISTA

RESUMEN: El Trastorno del Espectro Autista (TEA) es uno de los trastornos del neurodesarrollo que también se caracteriza por conductas excesivamente repetitivas, intereses restringidos e insistencia en lo mismo, además de déficits en la comunicación y la interacción social. Este artículo presenta un análisis de las acciones y estrategias propuestas para la inclusión de estudiantes con TEA en la educación básica en el municipio de Jataí-GO. Para ello, se identificó la meta 04, del Plan Municipal de Educación del municipio de Jataí-GO, relacionada con el tema y solo se seleccionaron estrategias que, de alguna manera, satisfagan las necesidades del estudiante con TEA. Posteriormente, también se analizó el Informe de Actividad (bienio 2015-2017) para verificar si estas estrategias ya se estaban implementando. Luego del análisis, se observó que las estrategias abordan, de manera genérica, la TEA y las prácticas pedagógicas educativas a adoptar, siendo más evidente solo la creación del Servicio Educativo Especializado (AEE) en la tarde.

PALABRAS CLAVE: Trastorno del Espectro Autista. Inclusión Escolar. Prácticas Pedagógicas. Plan de Educación Municipal.

\section{REFERÊNCIAS}

AMERICAN PSYCHIATRIC ASSOCIATION. Manual de diagnóstico e estatístico de transtornos mentais: DSM-5. 5. ed. Porto Alegre: Artmed, 2014.

BENINI, W.; CASTANHA, ANDRÉ P. A inclusão do aluno com transtorno do espectro autista na escola comum: Desafios e Possibilidades. Cadernos PDE, 2016.

BRASIL. Ministério da Educação/Secretaria de Educação Especial. Manual de Orientação: Programa de Implantação de Sala de Recursos Multifuncionais. 2010. Disponível

http://portal.mec.gov.br/index.php?option=com_docman\&view=download\&alias=9936 -manual-orientacao-programa-implantacao-salas-recursosmultifuncionais\&ltemid=30192. Acesso em: 05 jun. 2020. 
MONTEL. L. M.; SOUZA, R. R. DE, LEMOS, L. S

BRASIL. Ministério da Educação/ Secretaria de Educação Continuada, Alfabetização, Diversidade e Inclusão (MEC/SICADI). Política Nacional de Educação Especial na Perspectiva da Educação Inclusiva; 2014a. Disponível em: http://portal.mec.gov.br/index.php?option=com_docman\&view=download\&alias=1669 0-politica-nacional-de-educacao-especial-na-perspectiva-da-educacao-inclusiva05122014\&ltemid=30192. Acesso em: 20 abr. 2020.

BRASIL. Ministério da Educação/ Secretaria de Articulação com os Sistemas de Ensino (MEC/ SASE). O Plano Municipal de Educação: Caderno de Orientação. 2014b. Disponível em: http://pne.mec.gov.br/images/pdf/pne_pme_caderno_de_orientacoes.pdf. Acesso em: 08 dez. 2019.

BRASIL. Lei $n^{\circ} 13.861$, de 18 de julho de 2019. Altera a Lei $n^{\circ} 7.853$, de 24 de outubro de 1989, para incluir as especificidades inerentes ao transtorno do espectro autista nos censos demográficos. Brasília, DF, 2019.

BRASIL. Lei n' 13.977, de 8 de janeiro de 2020. Altera a Lei no 12.764, de 27 de dezembro de 2012 (Lei Berenice Piana), e a Lei n 9.265, de 12 de fevereiro de 1996, para instituir a Carteira de Identificação da Pessoa com Transtorno do Espectro Autista (Ciptea), e dá outras providências. Brasília, DF, 2020.

CABRAL, C. S.; MARIN, A. H. Inclusão escolar de crianças com transtorno do espectro Autista: uma revisão sistemática da literatura. Educação em Revista, n. 33, 2017.

DEPARTAMENTO CIENTÍFICO DE PEDIATRIA DO DESENVOLVIMENTO E COMPORTAMENTO. Manual de Orientação: Transtorno do Espectro Autista. Sociedade Brasileira de Pediatria, n. 05, 2019.

DIÁRIO OFICIAL ELETRÔNICO DO MUNICÍPIO DE JATAÍ -GO. Plano Municipal de educação. Ano 03 / 516 Edição / Vigência 26/06/2015. Disponível em: http://www.jatai.go.gov.br/secretaria-de-educacao/plano-municipal-de-educacao/.

Acesso em: 04 dez. 2019.

DICIO. Dicionário online de Português. Disponível em: https://www.dicio.com.br/inclusao/. Acesso em: 05 nov. 2020.

GIL, A.C. Como elaborar projetos de pesquisa. 4. ed. São Paulo: Atlas, 2002.

GOMES, P.T.; LIMA, L.H.; Bueno M.K.; Araújo L.A.; Souza N.M. Autism in Brazil: a systematic review of family challenges and coping strategies. Jornal de Pediatria, n. 191, 2015, p. 111-121.

KLIM, A. Autismo e Síndrome de Asperger: uma visão geral. Revista Brasileira de Psiquiatria, n. 1 v. 28, 2006. 
MARQUES, Heitor R. Metodologia da pesquisa e trabalho científico. 4. ed. rev. atual. Campo Grande. UCBD, 2014.

NUNES, D.R.P.; AZEVEDO, M.Q.O.; SCHIMIDT, C. Inclusão educacional de pessoas com Autismo no Brasil: uma revisão da literatura. Revista Educação Especial, v. 26, n. 47, p. 557-572, 2013.

NUNES, C.; MADUREIRA, I. Desenho Universal para a Aprendizagem: Construindo práticas pedagógicas inclusivas. Revista da Investigação às Práticas, versão on-line ISSN 21821372, v. 5, n. 2, 2015.

ORGANIZAÇÃO PAN-AMERICANA DA SAÚDE - OPAS. Folha informativa - Transtorno do espectro autista, 2017.2 Disponível em: https://www.paho.org/bra/index.php?ltemid=1098. Acesso em: 18 mai. 2020.

PAIVA JR, F. Quantos autistas há no Brasil? Revista Autismo, nº 04, ano V, 2019.

PEREIRA. D.M. Análise dos Efeitos de um Plano Educacional Individualizado no Desenvolvimento Acadêmico e Funcional de um aluno com Transtorno de Espectro do Autismo. 2104. Dissertação (Mestrado em Educação) - Universidade Federal do Rio Grande do Norte. Rio Grande do Norte.

PORTAL DO ESPECTRO AUTISTA. Prevalência do TEA. Publicado em 21 de fev. de 2020. Disponível em: https://www.instagram.com/p/B800aPvF1fP/. Acesso em: 19 mai, 2020.

TAVARES, A; STACHEWSKI, A.L. Os diferentes olhares sobre o autismo. Revista Veja Saúde, 2017. Disponível em: https://saude.abril.com.br/especiais/os-diferentes-olharessobre-o-autismo/. Acesso em: 19 mai. 2020.

TOKARNIA, M. Cresce o número de estudantes com necessidades especiais. Publicado em 31/01/2019. Disponível em: https://agenciabrasil.ebc.com.br/educacao/noticia/2019-01/cresce-o-numero-deestudantes-com-necessidades-especiais. Acesso em: 18 mai. 2020.

Lays Monezı MONTEL: Especialização em Docência Profissional, Técnica e Tecnológica pelo Instituto Federal de Educação, Ciência e Tecnologia de Goiás - IFG - Campus Jataí. Orcid: https://orcid.org/0000-0003-3756-3571

E-mail: laysmonezi@gmail.com

RITA Rodrigues DE SouzA: Doutora em Estudos Linguísticos na área de concentração Linguística Aplicada pelo Programa de Estudos Linguísticos da Universidade Estadual Paulista - Câmpus São José do Rio Preto. Possui graduação em Letras, Licenciatura 
MONTEL. L. M.; SOUZA, R. R. DE, SILVA, L. L.

Português/ Espanhol pela Universidade Federal de Goiás (2001) e mestrado em Letras e Linguística nessa mesma universidade em 2004, especialização em Educação a Distância pelo SENAC/DF (2008) e em Psicopedagogia Institucional pela Universidade Gama Filho (2011). Atualmente, é professora efetiva no Instituto Federal de Educação de Goiás - IFG/Câmpus de Jataí.

Orcid: https://orcid.org/0000-0002-0596-6985

E-mail: rita.souza@ifg.edu.br

LAísSe SILVA LemOS: Possui Licenciatura em Ciências Sociais pela Universidade Federal de Goiás (2008) e graduação em Bacharelado em Ciências Sociais pela Universidade Federal de Goiás (2008). Possui sraduação em Pedagogia, na modalidade de licenciatura plena, pela Fundação Antares de Ensino Superior com conclusão em outubro de 2012. Especialização na área de Educação Especial pela Universidade Federal de Goiás (2015). Professora pesquisadora efetiva do Instituto Federal de Educação, Ciência e Tecnologia de Goiás - IFG- Campus Jataí.

Orcid: https://orcid.org/0000-0003-4400-0371

E-mail: laisse.sobral@ifg.edu.br

Este periódico utiliza a licença Creative Commons Attribution 3.0, para periódicos de acesso aberto (Open Archives Iniciative - OAI). 